\title{
HYPERURICAEMIA- AN INDEPENDENT PREDICTOR OF ACUTE STROKE AND ITS OPTIMAL LEVEL TO PREVENT STROKE
}

\author{
Arunraj Ezhumalai', Chandrakala Karuppasami², Ravikumar V33 \\ ${ }^{1}$ Senior Assistant Professor, Department of Neurology, MGMGH attached to KAPV Government Medical College, Trichy \\ 2Postgraduate Student, Department of Biochemistry, MGMGH attached to KAPV Government Medical College, Trichy \\ 3 Professor \& HOD, Department of Neurology, MGMGH attached to KAPV Government Medical College, Trichy
}

\begin{abstract}
BACKGROUND

Stroke ranks as a third most common cause of mortality in the world after ischaemic heart disease and malignancy in the elderly. The prevalence of hyperuricaemia in stroke is $35.2 \%$ in men and $8.7 \%$ in women in developing countries, and it is significantly higher in patients with acute stroke than the normal population. Serum uric acid role in stoke is controversial. Serum uric acid is a soluble pro-oxidant and antioxidant.

Aim and Objectives- The present study aims to find serum uric acid levels in acute stroke patients and assess its relationship with other risk factors such as FBS, Lipid Profile, Hypertension, Alcohol, and Smoking and to find optimal level below which stroke can be prevented.
\end{abstract}

\section{MATERIALS AND METHODS}

In this case control study, we assessed a hundred patients with acute stroke (confirmed by CT and MRI Brain) who were admitted in MGMGH, Trichy, and hundred age and sex matched controls from November 2016 to January 2017. Patients with a known risk for cardioembolic disorders and hyperuricaemia were excluded from this study. Clinical records of patients, age and sex matched controls and their serum uric acid (Uricase Method), FBS (GOD-POD), Lipid Profile levels (Direct) were investigated. Finally, data were analysed using SPSS software 19.

\section{RESULTS}

Hundred acute stroke patients and controls were studied. Mean age of the patients was $56.2 \pm 13.01$ years. Mean serum uric acid level in stroke patients $(6.07 \pm 0.88)$ is higher than in control group $(5.1 \pm 0.93)$. There was a significant change of uric acid comparison between patients and control $(\mathrm{P}=0.001)$. There was no significant correlation between TGL, VLDL, FBS, Hypertension, Smoking and Alcohol between patients and control. $\mathrm{P} \leq 0.05$ was considered significant. Uric acid is a significant risk factor for acute stroke.

\section{CONCLUSION}

Significant increase in serum uric acid level in patients with acute stroke indicates that it can be considered as an independent risk factor of acute stroke and management of hyperuricaemia and maintaining optimal level of below $5.2 \mathrm{mg} \%$ and $4.3 \mathrm{mg} \%$ in males and females can be useful to prevent stroke.

\section{KEYWORDS}

Serum Uric Acid, Acute Ischaemic Stroke, Antioxidant, Hyperuricaemia.

HOW TO CITE THIS ARTICLE: Ezhumalai A, Karuppasami C, Ravikumar V. Hyperuricaemia- An independent predictor of acute stroke and its optimal level to prevent stroke. J. Evolution Med. Dent. Sci. 2017;6(44):3446-3451, D0I: 10.14260/Jemds/2017/746

\section{BACKGROUND}

Cerebrovascular diseases are the most common and devastating disorders that embrace ischaemic stroke and haemorrhagic stroke. Stroke is one of the leading causes of mortality and morbidity in India. The estimated adjusted prevalence rate of stroke in India ranges from 84-262/lakh in rural area and 334-424/lakh in urban areas.[1]. A stroke is defined as "abrupt onset of a focal neurologic deficit that is attributed to a focal vascular cause.

Financial or Other, Competing Interest: None.

Submission 19-04-2017, Peer Review 18-05-2017,

Acceptance 25-05-2017, Published 01-06-2017.

Corresponding Author:

Arunraj Ezhumalai,

No.1. North New Paikara Street,

Woraiyur, Trichy-620003

Tamilnadu.

E-mail: dr.e.arunraj@gmail.com

DOI: $10.14260 /$ jemds $/ 2017 / 746$

(c) $($ i) $(9)$
Hence, for the definition of stroke, both clinical and brain imaging are necessary to support the diagnosis". After Ischaemic heart disease and cancer especially in the elderly, stroke ranks as the third most common cause of mortality in the world. The mortality rate of acute stroke is as high as $20 \%$ and it stands higher even after many years following the acute stroke event in patients on comparison with the general population. Stroke is the second cause of disability status and vascular dementia in adults aged $\geq 65$. The prevalence of hyperuricaemia in stroke is $35.2 \%$ in men and $8.7 \%$ in women in developing countries and it is significantly higher in patients with acute stroke than normal population. ${ }^{[2,3]}$ Uric acid is the main end catabolite of purine cycle metabolism in humans and higher primates. It is cleared from the plasma through the kidney. Uric acid level changes by age and sex. Before puberty, the mean serum uric acid is $3.6 \mathrm{mg} / \mathrm{dL}$ for both sexes. Following puberty, value raises to adult levels for female 2.5 to $6 \mathrm{mg} / \mathrm{dL}$, male $3.5-7 \mathrm{mg} / \mathrm{dL}$, typically in the female the value is $1 \mathrm{mg} / \mathrm{dL}$ less than men. Lower level in 
women apparently is due to increased renal urate clearance by oestrogen. $[3,4,5]$ It has been reported that increased levels of serum uric acid are associated with established cerebrovascular risk factors like elevated serum triglyceride and LDL, VLDL levels, obesity, hypertension, metabolic syndrome and Insulin resistance.[6] But uric acid also shows neuroprotective effects by acting as a free radical scavenger.[7,8] In humans, approximately fifty percent of antioxidant capacity of plasma comes from uric acid. ${ }^{[8,9]}$ So the role of uric acid in stroke is controversial. Therefore, it is unclear whether serum uric acid acts as pro-oxidant or antioxidant in the development of the cerebrovascular disease. Hence, to alleviate this controversy it was decided to carry out the present study of uric acid levels in patients of the acute stroke. The contraflexural point of serum uric acid level is to be assessed for the purpose to treat the patients and to prevent fatal complications of an acute stroke.

\section{Aims and Objectives \\ In this study, we determined the association between Serum Uric Acid (SUA) levels in acute stroke. Further, we assessed its relationship with other risk factors such as FBS, Lipid Profile, Hypertension, Alcohol, and Smoking. We aimed at finding the optimal level of uric acid below which stroke incidence can be prevented.}

\section{MATERIALS AND METHODS}

\section{Study Design}

In this case control study, we assessed a hundred patients with acute stroke (Confirmed by CT and MRI Brain) who were admitted in MGMGH, Trichy, Tamil Nadu, and hundred age and sex matched controls who came to Noncommunicable disease Outpatient Department MGMGH, Trichy were studied from November 2016 to January 2017. Controls need not be in good health; inclusion of sick people is sometimes appropriate, as the control group should represent those at risk of becoming a case.[9,10] Controls should come from the same population as the cases.[10] The controls attending in our non-communicable outpatient department may have hypertension, diabetes or smokers and they also have the risk of stroke. Sample size of 100 patients and 100 controls was taken. Sample size was determined with Power of $80 \%$; Confidence Interval of 95\%; Odds Ratio at 2.24 and ratio of control to case being one. Percentage of controls exposed was $40.5 \%$ and Percentage of cases exposed was $60.3 \%$. The estimated sample size based on mean and standard deviation formula is $52+52$. The same has been confirmed using continuity correction formula to estimate sample size as 100 .

Patients with a known risk for thromboembolic disorders and other causes of hyperuricaemia were excluded from this study. All patients and control group were informed and the consent was obtained. Age, Sex, History of Smoking, Alcoholism, Diabetes Mellitus, Hypertension and their duration was asked from the study groups. Baseline blood pressure was recorded in supine posture on admission. Within 24 hours of admission into the hospital, blood samples were collected from the study groups and their Serum Uric Acid (Uricase Method), Fasting Blood Sugar (GOD-POD method), Total Cholesterol (Direct Method), Triglyceride (Direct Method), Very Low Density Lipoprotein (Direct Method), Low Density Lipoprotein (Direct Method), High
Density Lipoprotein (Direct Method) Urea and Creatinine (Kinetic methods) levels were estimated in 24 hours central Biochemistry Laboratory. All patients underwent CT Brain scan. Stroke types were classified into the Ischaemic stroke and haemorrhagic stroke according to CT Brain. All patients received stroke management as per current guidelines.

Hypertension is considered here as blood pressure more than $140 / 90 \mathrm{mmHg}$ on at least two occasions or with past history of systemic hypertension or ongoing treatment for systemic hypertension. Diabetes is considered here as fasting plasma glucose of $\geq 126 \mathrm{mg} / \mathrm{dL}$ or postprandial $>200 \mathrm{mg} / \mathrm{dL} 2$ hours after oral glucose load or random blood sugar level $>200 \mathrm{mg} / \mathrm{dL}$ in symptomatic patients or history of receiving treatment for diabetes mellitus or diagnosed in past as diabetes mellitus. A person who smoked at least 10 cigarettes per day for a minimum of 6 months or who has smoked more than 1 year daily or irrespective of the count of cigarettes smoked per day were considered as a smoker. ${ }^{[5]}$

\section{Ethics Committee}

This study was approved by the Ethical Committees of the K.A.P. Viswanathan Government Medical College, Trichy, Tamil Nadu. Informed consent was obtained from both patients group and control group who participated in this study.

\section{Exclusion Criteria}

Patients with following diseases were excluded in this study1. Patients having a risk for cardiac emboli like Atrial fibrillation, Valvular heart disease, patients on anticoagulant treatment; 2. Onset of stroke symptoms more than 48 hours; 3. Previous history of vascular disease like Stroke, Ischaemic heart disease, thrombolysis, peripheral artery disease; 4. Patients receiving drugs altering Serum uric acid levels like Diuretics, Angiotensin receptor blockers, Allopurinol, Febuxostat, Atorvastatin, Fenofibrate; 5. Active infections; 6. Cancer Patients and patients on Chemotherapy; 7. Hepatic or renal diseases; 8 . Thyroid disorders; 9. Chronic obstructive lung disease; 10 . Inflammatory bowel disease and 11. Gout.

\section{Statistical Analysis}

Statistical analysis was done using SPSS software for windows version 19. Mean and standard deviation (SD) of all continuous data are reported. To compare means in two independent groups (like Hypertensive and NonHypertensive), independent samples T-test in normally distributed variables and Levene's Test for Equality of Variances and Two-Sample Kolmogorov-Smirnov Test were used for Frequencies. Chi-square test was used for nominal data comparison and Pearson correlation test was used to determine the relation between two continuous variables. $\mathrm{R}$ was reported for correlation tests. The level of significance was considered if $\mathrm{p} \leq 0.05$.

\section{RESULTS}

Hundred acute stroke patients were studied of whom 45 were female and 55 were male. In these, $92 \%$ had ischaemic stroke, $8 \%$ had haemorrhagic stroke. Regarding the data obtained mean serum uric acid level in patients was higher $(6.076 \pm 0.88)$ than control group $(5.173 \pm 0.93)$ as per table1. There was significant change between patients and control $(\mathrm{P}=0.001)$. Based on the definition of the high uric acid level 
greater than $7 \mathrm{mg} / \mathrm{dL}$ in men and $6 \mathrm{mg} / \mathrm{dL}$ in women, $47.3 \%$ patients had hyperuricaemia. There was no statistically significant difference observed between age of the patients and serum uric acid level. But difference in uric acid level between men and women was statistically significant ( $\mathrm{p}=0.03$, table 2). 36 patients had a known history of diabetes mellitus and 9 patients had diabetes diagnosed by admission blood tests. Baseline means blood pressure of the patients was 135/80 mmHg after stroke; $40 \%$ had a known history of hypertension; $26.3 \%$ patients had a historyof smoking. According to table 2, the difference in sugar between patients and control $(\mathrm{p}=0.0796)$ is not statistically significant. There was no statistically significant difference in urea $(p=0.82)$ and creatinine $(p=0.276)$ levels between patients and control group. A p-value $<0.05$ was considered significant.

\begin{tabular}{|c|c|c|c|c|}
\hline Variables & Group & Mean & Std. Deviation & p-value \\
\hline \multirow{2}{*}{ SBP } & Patients & 126.50 & 18.098 & \multirow{2}{*}{0.139} \\
\hline & Control & 123.20 & 12.861 & \\
\hline \multirow{2}{*}{ DBP } & Patients & 80.50 & 11.645 & \multirow{2}{*}{0.769} \\
\hline & Control & 81.00 & 12.350 & \\
\hline \multirow{2}{*}{ UREA } & Patients & 37.04 & 5.195 & \multirow{2}{*}{0.828} \\
\hline & Control & 36.88 & 5.207 & \\
\hline \multirow{2}{*}{ SUGAR } & Patients & 133.80 & 49.210 & \multirow{2}{*}{0.079} \\
\hline & Control & 130.28 & 38.346 & \\
\hline \multirow{2}{*}{ CREATI } & Patients & 1.018 & 0.6269 & \multirow{2}{*}{0.276} \\
\hline & Control & 0.947 & 0.1690 & \\
\hline \multirow{2}{*}{ TCHO } & Patients & 206.13 & 57.659 & \multirow{2}{*}{0.846} \\
\hline & Control & 207.60 & 49.159 & \\
\hline \multirow{2}{*}{ TGL } & Patients & 169.35 & 76.588 & \multirow{2}{*}{0.435} \\
\hline & Control & 160.85 & 77.020 & \\
\hline
\end{tabular}

\begin{tabular}{|c|c|c|c|c|}
\hline \multirow{2}{*}{ VLDL } & Patients & 33.870 & 15.3176 & \multirow{2}{*}{0.435} \\
\cline { 2 - 4 } & Control & 32.170 & 15.4040 & \\
\hline \multirow{2}{*}{ LDL } & Patients & 133.49 & 50.589 & \multirow{2}{*}{0.564} \\
\cline { 2 - 4 } & Control & 137.42 & 45.487 & \\
\hline \multirow{2}{*}{ HDL } & Patients & 38.78 & 4.191 & \multirow{2}{*}{0.303} \\
\cline { 2 - 4 } & Control & 38.01 & 6.159 & \\
\hline \multirow{2}{*}{ UA } & Patients & 6.076 & 0.8863 & \multirow{2}{*}{0.001} \\
\cline { 2 - 4 } & Control & 5.173 & 0.9314 & \\
\hline
\end{tabular}

Table 1. Laboratory Findings at the time of Patient's Admission, Control Group Summarised in Value of Mean, Standard Deviation, and $P$-Value

\begin{tabular}{|c|c|c|c|c|}
\hline \multirow{2}{*}{ Sex } & \multirow{2}{*}{ Total Number } & \multicolumn{2}{|c|}{ Uric Acid } & \multirow{2}{*}{ p-value } \\
\cline { 3 - 4 } & & Mean & SD & \\
\hline Male & 45 & 6.23 & 0.87 & \multirow{2}{*}{0.03} \\
\hline Female & 55 & 5.949 & 0.89 & \multirow{2}{|c|}{0.03} \\
\hline \multicolumn{3}{|r|}{ Table 2. Mean and Standard Deviation of } \\
Serum Uric Acid Level in Female and Male \\
\hline
\end{tabular}

\begin{tabular}{|c|c|c|}
\hline \multirow{2}{*}{ Age Group } & \multirow{2}{*}{ Total Number } & UA \\
\cline { 2 - 3 } & & MEAN \pm SD \\
\hline $20-40$ & 14 & $5.87 \pm 0.8$ \\
\hline $40-60$ & 34 & $6.19 \pm 0.81$ \\
\hline$>60$ & 52 & $6 \pm 0.9$ \\
\hline \multicolumn{2}{|c|}{ Table 3. SUA in Different Age Group of Patients } \\
in Value of Mean, Standard Deviation \\
\hline
\end{tabular}

\begin{tabular}{|c|c|c|c|c|c|c|c|c|c|c|c|}
\hline \multicolumn{2}{|c|}{ Variables } & SBP & DBP & UREA & SUG & TCHO & TGL & VLDL & LDL & HDL & UA \\
\hline \multirow{2}{*}{ SBP } & Pearson & 1 & 0.656 & 0.088 & 0.093 & 0.038 & 0.083 & 0.083 & 0.027 & -0.108 & 0.194 \\
\hline & Sig. & & 0.000 & 0.213 & 0.192 & 0.596 & 0.240 & 0.240 & 0.702 & 0.129 & 0.006 \\
\hline \multirow{2}{*}{ DBP } & Pearson & $0.656^{* *}$ & 1 & 0.005 & $0.147^{*}$ & 0.020 & 0.130 & 0.130 & -0.001 & $-.168^{*}$ & 0.060 \\
\hline & Sig. & 0.000 & & 0.940 & 0.037 & 0.778 & 0.067 & 0.067 & 0.993 & 0.018 & 0.401 \\
\hline \multirow{2}{*}{ UREA } & Pearson & 0.088 & 0.005 & 1 & $0.189^{* *}$ & $0.196^{* *}$ & $0.238^{* *}$ & $0.238^{* *}$ & $0.142^{*}$ & 0.005 & 0.012 \\
\hline & Sig. & 0.213 & 0.940 & & 0.007 & 0.005 & 0.001 & 0.001 & 0.045 & 0.944 & 0.861 \\
\hline \multirow{2}{*}{ SUG } & Pearson & 0.093 & $0.147^{*}$ & $0.189^{* *}$ & 1 & -0.038 & -0.039 & -0.039 & -0.022 & -0.064 & 0.025 \\
\hline & Sig. & 0.192 & 0.037 & 0.007 & & 0.597 & 0.582 & 0.582 & 0.754 & 0.367 & 0.730 \\
\hline \multirow{2}{*}{ TCHO } & Pearson & 0.038 & 0.020 & $0.196^{* *}$ & -.038 & 1 & $0.495^{* *}$ & $0.495^{* *}$ & $0.961^{* *}$ & -0.059 & 0.084 \\
\hline & Sig. & 0.596 & 0.778 & 0.005 & 0.597 & & 0.000 & 0.000 & 0.000 & 0.408 & 0.235 \\
\hline \multirow{2}{*}{ TGL } & Pearson & 0.083 & 0.130 & $0.238^{* *}$ & -0.039 & 0.495 & 1 & $1.000^{* *}$ & 0.255 & -0.21 & 0.050 \\
\hline & Sig. & 0.240 & 0.067 & 0.001 & 0.582 & 0.000 & & 0.000 & 0.000 & 0.002 & 0.484 \\
\hline \multirow{2}{*}{ VLDL } & Pearson & 0.083 & 0.130 & $0.238^{* *}$ & -0.039 & $0.495^{* *}$ & $1.000^{* *}$ & 1 & $0.255^{* *}$ & $0.216^{* *}$ & 0.050 \\
\hline & Sig & 0.240 & 0.067 & 0.001 & 0.582 & 0.000 & 0.000 & & 0.000 & 0.002 & 0.484 \\
\hline \multirow{2}{*}{ LDL } & Pearson & 0.027 & -0.001 & $0.142^{*}$ & -0.022 & $0.961^{* *}$ & $0.255^{* *}$ & $0.255^{* *}$ & 1 & -0.106 & 0.085 \\
\hline & Sig. & 0.702 & 0.993 & 0.045 & 0.754 & 0.000 & 0.000 & 0.000 & & 0.135 & 0.233 \\
\hline \multirow{2}{*}{ HDL } & Pearson & 0.108 & -0.168 & 0.005 & -0.064 & -0.059 & -0.216 & -0.216 & -0.106 & 1 & -0.059 \\
\hline & Sig. & 0.129 & 0.018 & 0.944 & 0.367 & 0.408 & 0.002 & 0.002 & 0.135 & & 0.405 \\
\hline \multirow{2}{*}{ UA } & Pearson & $0.194^{* *}$ & 0.060 & 0.012 & 0.025 & 0.084 & 0.050 & 0.050 & 0.085 & -0.059 & 1 \\
\hline & Sig. & 0.006 & 0.401 & 0.861 & 0.730 & 0.235 & 0.484 & 0.484 & 0.233 & 0.405 & \\
\hline \multicolumn{12}{|c|}{$\begin{array}{l}\text { Table 4. Correlations of Other Risk Factors of Stroke and Uric Acid } \\
\text { between Patients and Control Group by Pearson Correlation Test }\end{array}$} \\
\hline
\end{tabular}




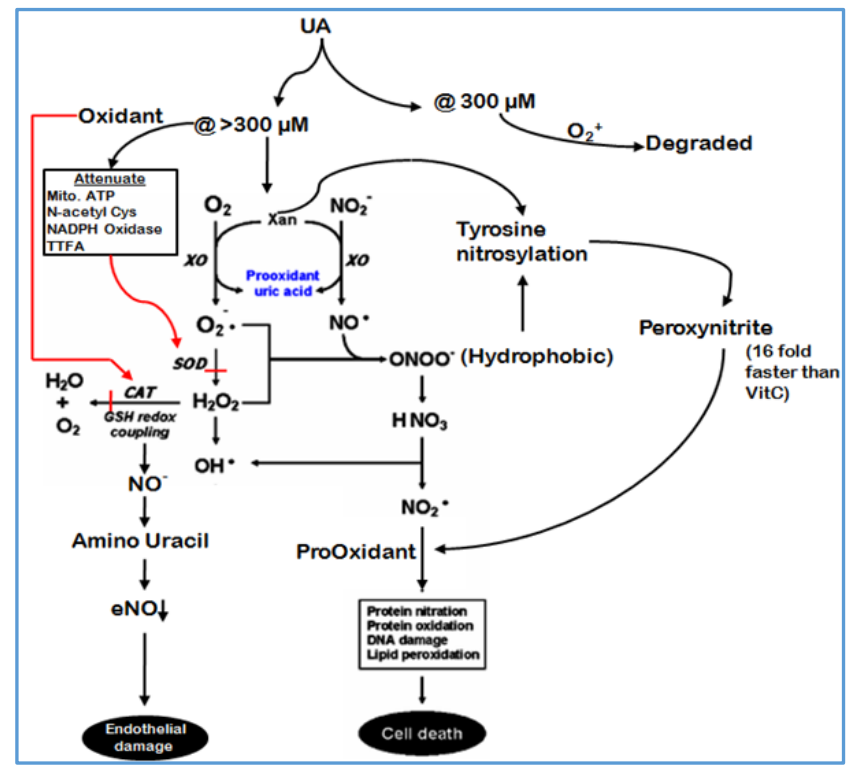

Figure 1. Pathophysiology of Stroke in Hyperuricaemia

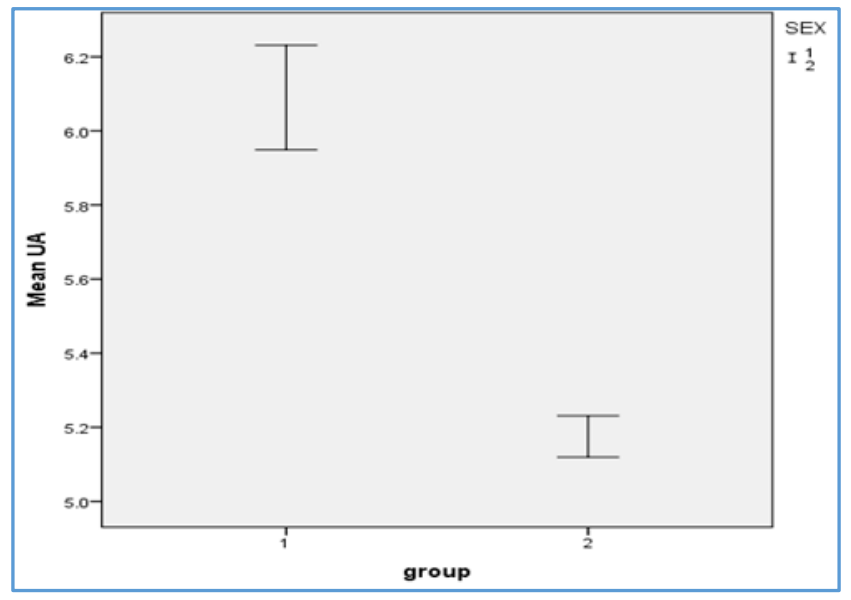

Figure 2. Mean Serum Uric Acid level in Patients (Group 1) \& Controls (Group 2)

\section{DISCUSSION}

Studies investigating the relationship among the uric acid and stroke have been inconsistent. Serum uric acid is a soluble antioxidant scavenger, and the increase in serum uric acid forms a marker of acute endothelial dysfunction and an important feature of the metabolic syndrome.[2] Hyperuricaemia has been found to be associated with raised endothelin levels, $[11,12,13]$ involved in the process of thrombus formation. Recent experimental studies on pathogenetic role for uric acid in vascular disease have demonstrated that hyperuricaemia is associated with endothelial dysfunction, generation of local oxidants, increased circulating levels of systemic inflammatory markers like monocyte chemoattractant protein-1, tumour necrosis factor- $\alpha$, interleukins like $1 \beta$ and interleukin- 6 , and smooth muscle proliferation.[14,15,16,17,18] A retrospective analysis of hospitalisation records of 2495 patients has demonstrated that raised serum uric acid level on admission predicted poor outcome on morbidity following ischaemic stroke.[3] By contrast, a prospective study with 881 patients has found that higher level of serum uric acid predicted better outcomes following a stroke, suggesting that serum urate may be beneficial.[4,5] There is little information about the role of uric acid as a risk factor or beneficial factor for vascular disease and acute stroke and so in this study we decided to find out the association of uric acid with cerebrovascular risk factor such as elevated serum cholesterol and triglyceride levels, systemic hypertension, smoking and alcohol.[2,6,19,20] The mechanism of this strong association between triglyceride levels and serum uric acid levels has to be elucidated. Uric acid (UA) is an endogenously produced water-soluble prooxidant and antioxidant that is modified by both drug and diet.[1] Serum uric acid (SUA) can work as a pro-oxidant under certain circumstance when other antioxidants like vitamin $C$ are low.[21] Increased SUA can cause endothelial dysfunction which can lead to vascular damage,[3] promote ox -LDL cholesterol[4] associated with increased release of inflammatory markers in circulation, and uric acid is also found in atherosclerotic plaque. Another mechanism is high uric acid level causes increased activity of xanthine oxidase which leads to the generation of superoxide anions and the reactive oxygen species in the human vasculature. ${ }^{[5,22,23]}$

In this study, we determined the serum uric acid levels were high in patients with acute stroke and about $47.3 \%$ percent of patients were hyperuricaemic based on definition of the high uric acid level (more than $7 \mathrm{mg} / \mathrm{dL}$ in men and more than 6 in women). According to this study, Serum Uric acid level was significantly higher in patients with acute stroke than the normal population. Regarding the data obtained mean serum uric acid level in patients was (6.076 \pm $0.88)$ than in control group $(5.173 \pm 0.93)$ as per Table 1 , There was significant change between patients and control $(\mathrm{P}=0.001)$ which is in comparison with many studies. Milionis et al[14] observed that the SUA levels were significantly elevated in acute stroke patients when compared with controls $(5.6 \pm 1.7 \mathrm{mg} / \mathrm{dL}$ vs. $4.8 \pm 1.4 \mathrm{mg} / \mathrm{dL}, \mathrm{P}<0.001)$. Srikrishna R and Suresh DR[24] found that serum uric acid levels were significantly higher in cases as compared to controls $(6.56 \pm 0.73$ vs. $4.66 \pm 0.47, \mathrm{P}<0.05)$. In the Rotterdam study, high serum uric acid levels were associated with the risk of stroke.

Patients' mean serum triglyceride level was $169.35 \pm$ $76.588 \mathrm{mg} / \mathrm{dL}$ while in control group it was $160.85 \pm 77.020$ $\mathrm{mg} / \mathrm{dL}$; patients' serum total cholesterol level was $206.13 \pm$ 57.65 while in control group mean serum total cholesterol level was $205.60 \pm 49.159$; Low-density lipoprotein (LDL) in patients and controls was $133.49 \pm 50.58$ and $132.42 \pm$ 45.487 and high-density lipoprotein (HDL) level was $38.78 \pm$ 4.19 and $38.01 \pm 6.15$. In this study, there is an inverse correlation between serum uric acid levels and HDL cholesterol, and a positive correlation with triglyceride levels ( $r=-0.334, \mathrm{P}=0.001$ for HDL and $\mathrm{r}=0.294, \mathrm{P}=0.001$ for triglycerides). Lehto et al[25] concluded that SUA was significantly associated with HDL cholesterol $(\mathrm{r}=-0.25, \mathrm{P}<$ $0.01)$ and triglyceride levels $(r=0.14, P<0.01)$. Bansal et al found a significant relationship among serum uric acid levels and triglyceride $(\mathrm{P}<0.05)$. Our findings correlate with the above mentioned studies.

In our study, higher serum uric acid levels have been observed in males $(6.23 \pm 0.87)$ on comparison to females (5.949 \pm 0.89$)$. There was a statistically significant difference in uric acid level between men and women ( $p=0.03)$, as per Table 2. Pearce et al (1969) observed higher SUA values in males as compared to females $(5.28 \pm 0.66$ vs. $4.47 \pm 0.78$ 
$\mathrm{mg} / \mathrm{dL})^{[26]}$ B. Longo-Mbenza et al[27] found significantly higher SUA level in males ( $6.6 \pm 7$ vs. $5.8 \pm 6 \mathrm{mg} / \mathrm{dL}, \mathrm{P}<0.01$ ). The results were consistent with the study by Milionis et al.[14] There was no significant relationship between age of the patients and serum uric acid level in our study, in contrast to other studies.

But uric acid level is a double edged weapon viz coming to the antioxidant property of uric acid, there have been several studies supporting the people with elevated serum uric acid level have a decreased incidence of idiopathic PD. In 1996, Davis et al in the Honolulu Heart Program had said that men with uric acid levels more than median was found to have 40 percent reduction in the incidence of idiopathic PD. Studies showed the increased incidence of Parkinson's disease and morbidity due to disease progression when the uric acid level was low.[28] Andreadou et al in his study found reduced uric acid in the serum of PD patients. Also low plasma uric acid level were found to have an increased risk of PD. ${ }^{[29]}$ According to our study, the lower most level of uric acid above which the increased incidence of stroke is $5.2 \mathrm{mg} \%$ for males and $4.3 \mathrm{mg} \%$ for females. So the optimal level for serum uric acid to be maintained so that it does not have its deleterious side effects as a pro-oxidant and antioxidant will be around 5.2 $\mathrm{mg} \%$ for males and $4.3 \mathrm{mg} \%$ for females. Larger studies are required to find out this optimal level.

Furthermore, Allopurinol, a xanthine oxidase inhibitor reduces inflammatory markers in stroke.[5] SUA can act as an antioxidant and accounts for over fifty percentage of the scavenging activity of free radical blood[4] by quenching superoxide and singlet oxygen, and by protecting oxidation of vitamin $C$ by means of iron chelation. Others have shown the ability of vitamin $C$ to repair oxidised urate, thus reiterating antioxidant capacity by these two antioxidants.[5]In a recent randomised, placebo-controlled, crossover trial involving thirty adolescents with hyperglycaemia having newly diagnosed hypertension on treating with allopurinol, there was a significant reduction in blood pressure when compared to placebo. Clinical trials with longer follow-up has to be done for the role of urate lowering therapy such as allopurinol and febuxostat in hypertension and stroke. Hyperuricaemia is a new focus for risk factor treatment in the primary prevention of stroke.

\section{Limitations of this Study}

If we had used a cohort study, it would have been possible to assess the significant association between uric acid level and incidence of stroke, but this is only a case control study.

\section{CONCLUSION}

Our study showed that in patients with acute stroke, hyperuricaemia prevalence was significantly higher than the normal population. There was no correlation among age and the serum uric acid levels of patients. There is significant difference between sex of patients and their serum uric acid levels. Hyperuricaemia was also found to have increased triglycerides and LDL cholesterol. Hyperuricaemia is inversely related to HDL cholesterol level. Due to the high hyperuricaemia prevalence in acute stroke patients, and associated raised triglyceride and LDL cholesterol levels, it can be considered as an individual and significant risk factor for acute stroke. Elevations in Uric acid have been linked to other risk factors of stroke like insulin resistance, hypertension, as well as lipid abnormalities. In conclusion, though we control all other cardiovascular risk factors, there is a significant association among hyperuricaemia and stroke, suggesting that serum uric acid has to be considered as an independent predictor of stroke risk and not just a marker for the disease state. Hence, to prevent stroke it will be optimal to maintain serum uric acid level around $5.2 \mathrm{mg} \%$ for males and $4.3 \mathrm{mg} \%$ for females. Treatment aimed at reducing serum uric acid and maintaining an optimal level can be useful to prevent the fatal outcome of acute cerebrovascular events in people.

\section{ACKNOWLEDGMENTS}

Dr. Mary Lily, M.D. Dean, KAPV Government Medical College, Trichy; Dr. Anitha M.D., Medical Superintindent, MGMGH, KAPV Government Medical College, Trichy; Dr. K. Nirmala Devi D.C.H., M.D., Biochemistry Professor and HOD, Department of Biochemistry, Trichy.

\section{REFERENCES}

[1] Ferri CP, Schoenborn C, Kalra L, et al. Prevalence of stroke and related burden among older people living in Latin America, India, China. J Neurol Neurosurg Psychiatry 2011;82(10):1074-82.

[2] Bowman GL, Shannon J, Frei B, et al. Uric acid as a CNS antioxidant. J Alzheimers Dis 2010;19(4):1331-6.

[3] Patil TB, Pasari AS, Sargar KM, et al. Serum uric acid level in acute ischemic stroke: a study of 100 patients. J Neurol Res 2011;1(5):193-200.

[4] Mehrpour M, Khuzan M, Najimi N, et al. Serum uric acid level in acute stroke patients. Med J Islam Repub Iran 2012;26(2):66-72.

[5] Karagiannis A, Mikhailidis DP, Tziomalos K, et al. Serum uric acid as an independent predictor of early death after acute stroke. Circ J 2007;71(7):1120-7.

[6] Peng TC, Wang CC, Kao TW, et al. Relationship between hyperuricaemia and lipid profiles in US adults. BioMed Research International Article ID 127596, 2015;2015:1-7.

[7] Hellsten-Westing Y. Immunohistochemical localization of xanthine oxidase in human cardiac and skeletal muscle. Histochemistry 1993;100(3):215-22.

[8] Muir SW, Harrow C, Dawson J, et al. Allopurinol use yields potentially beneficial effects on inflammatory indices in those with recent ischemic stroke: a randomized, double-blind, placebo- controlled trial. Stroke 2008;39(12):3303-7.

[9] Grimes DA, Schulz KF. Compared to what? finding controls for case-control studies. Lancet 2005;365(9468):1429-33.

[10] Schulz KF, Grimes DA. Case-control studies: research in reverse. Lancet 2002;359(9304):431-4.

[11] Waring WS, Webb DJ, Maxwell SRJ. Effect of local hyperuricaemia on endothelial function in the human forearm vascular bed. $\mathrm{Br} \mathrm{J}$ Clin Pharmacol 2000;49:511.

[12] Corry DB, Eslami P, Yamamoto K, et al. Uric acid stimulates vascular smooth muscle cell proliferation and oxidative stress via the vascular renin-angiotensin system. J Hypertens 2008;26(2):269-275. 
[13] Bagnati M, Perugini C, Cau C, et al. When and why a water-soluble antioxidant becomes pro-oxidant during copper-induced low-density lipoprotein oxidation: a study using uric acid. Biochem J 1999;340(Pt 1): 143-52.

[14] Milionis HJ, Kalantzi KJ, Goudevenos JA, et al. Serum uric acid levels and risk for acute ischaemic nonembolic stroke in elderly subjects. J Intern Med 2005;258(5):435-41.

[15] Feig D, Soletsky B, Johnson R. Effect of allopurinol on blood pressure of adolescents with newly diagnosed essential hypertension. JAMA 2008;300(8):924-32.

[16] Kanellis J, Watanabe S, Li J, et al. Uric acid stimulates monocyte chemoattractant protein-1 production in vascular smooth muscle cells via mitogen-activated protein kinase and cyclooxygenase-2. Hypertension 2003;41(6):1287-93.

[17] Kang DH, Han L, Ouyang X, et al. Uric acid causes vascular smooth muscle cell proliferation by entering cells via a functional urate transporter. Am J Nephrol 2005;25(5):425-33.

[18] Rao GN, Corson MA, Berk BC. Uric acid stimulates vascular smooth muscle cell proliferation by increasing platelet-derived growth factor A-chain expression. J Bio Chem 1991;266(13):8604-8.

[19] Bos MJ, Koudstaal PJ, Hofman A, et al. Uric acid is a risk factor for myocardial infarction and stroke: the Rotterdam study. Stroke 2006;37(6):1503-7.

[20] Tan S, Radi R, Gaudier F, et al. Physiologic levels of uric acid inhibit xanthine oxidase in human plasma. Pediatr Res 1993;34(3):303-7.
[21] Abuja PM. Ascorbate prevents pro-oxidant effects of urate in the oxidation of human low-density lipoprotein. FEBS Lett 1999;446(2-3):305-8.

[22] Mozoșa I, Chiulana C, Goruna C. Serum uric acid in stroke. Series of Chemistry 2007;16(2):227-36.

[23] Higgins P, Dawson J, Walters M. The potential for xanthine oxidase inhibition in the prevention and treatment of cardiovascular and cerebrovascular disease. Cardiovasc Psychiatry Neurol 2009;2009:282059.

[24] Shrikrishna R, Suresh DR. Biochemical study of an antioxidant profile in acute ischemic stroke. British Journal of Medical Practitioners 2009;2(1):35-37.

[25] Lehto S, Niskanen L, Ronnemaa T, et al. Serum uric acid is a strong predictor of stroke in patients with non-insulin-dependent diabetes mellitus. Stroke 1998;29(3):635-9.

[26] Pearce J, Aziz H. Uric acid and plasma lipids in cerebrovascular disease. I. prevalence of hyperuricaemia. Br Med J 1969;4(5675):78-80.

[27] Longo-Mbenza B, Luila EL, Mbete $P$, et al. Is hyperuricaemia risk factor for stroke and coronary heart disease among Africans? Int J Cardiol 1999;71(1):17-22.

[28] Annanmaki T, Muuronen A, Murros K. Low plasma uric acid level in Parkinson's disease. Mov Disord 2007;22(8):1133-7.

[29] Andreadou E, Nikolaou C, Gournaras F, et al. Serum uric acid levels in patients with Parkinson's disease: their relationship to treatment and disease duration. Clin Neurol Neurosurg 2009;111(9):724-8. 